\title{
Cartilha Insurgente: por uma pedagogia que atravesse grades
}

\section{Insurgent Manual: for a pedagogy that crosses the bars}

\author{
Laís Jacques Marques \\ Universidade do Estado de Santa Catarina - UDESC, Florianópolis/SC, Brasil \\ E-mail: laisjacquesm@gmail.com \\ Bruna Luana Capelin Kunzler \\ Universidade Federal de Santa Maria - UFSM, Santa Maria/RS, Brasil \\ E-mail: brunalck@gmail.com \\ Marcia Berselli \\ Universidade Federal de Santa Maria - UFSM, Santa Maria/RS, Brasil \\ E-mail: bersellimarcia@gmail.com
}

\section{Resumo}

Esta cartilha pretende apresentar possíveis intervenções para desestabilizar sistemas que levam ao assujeitamento corporal pessoas consideradas marginalizadas pela estrutura dominante. Observaremos como práticas artísticas (ou práticas criativo-pedagógicas) podem contrapor as opressões cotidianas instauradas em regimes socioeducativos. Como suporte de reflexão, oficinas teatrais e artísticas realizadas em centros de internação, além de autoras e autores com as(os) quais dialogamos em busca de premissas para a ação.
This manual intends to present possible interventions to destabilize systems that lead people considered as marginalized by the dominant structure to corporal subjection. We will observe how artistic practices (or creative-pedagogical practices) can oppose the daily oppressions established in socio-educational regimes. As a support for reflection, theatrical and artistic workshops developed in detention centers, in addition to the dialogue with authors in search of premises for action. 


\section{Diga quem são suas(seus) aliadas(os)}

Para sair em busca de expressão artística em ambientes de privação de liberdade é necessário organização. Mostrar a quem nos aliamos é tarefa protetora. Queremos discutir com nossos pares, e é este o intuito do escrito: descobrir metodologias de ensino e aprendizagem que evidenciem percursos artístico-pedagógicos capazes de instaurar, mesmo em contexto de vigilância, a sensibilização. Nossas experiências enquanto educadoras na ala feminina em um regime socioeducativo de Santa Catarina ${ }^{1}$ nos servirão de cenário. Levaremos em consideração as reverberações de duas oficinas (uma permanente no local, a teatral ${ }^{2}$; e a outra o projeto de verão ${ }^{3}$, ensino livre de artes) - pequenos atos de rebeldia e afeto - realizadas no regime socioeducativo com jovens que cumprem medidas de ressocialização, e privadas de liberdade ${ }^{4}$.

Pretendemos ainda promover a discussão sobre o que pode a pedagogia das artes em ambientes de restrição de liberdade, e, para isto, contaremos com colaborações como as do teatrólogo brasileiro Augusto Boal (1931 - 2009), referentes aos processos desalienantes da prática do Teatro

10 referido Departamento de Administração Socioeducativo (DEASE) de Santa Catarina abriga aproximadamente 40 jovens entre 16 e 19 anos, e é dividido por gêneros: na ala masculina, o CASE (Centro de Acolhimento Socioeducativo) e na ala feminina, o CIF (Centro de Internação Feminina). Os trabalhos aqui relatados se deram somente na ala feminina, CIF, pois, na masculina, CASE, há maior resistência por parte da administração quanto ao desenvolvimento de atividades artísticas com os jovens, assunto para outro escrito. Aqui, nos ateremos às práticas já desenvolvidas.

2 Teatro e Prisão - práticas de infiltração das artes cênicas em espaços de vigilância, coordenado pelo Prof. Dr. Vicente Concilio, é um grupo de pesquisa e extensão fundado na Universidade do Estado de Santa Catarina UDESC em 2019 e contempla ações teatrais no Presídio Feminino e no regime socioeducativo em Santa Catarina.

3 Realizado pelo Centro de Educação de Jovens e Adultos, o Projeto de verão é uma parceria entre Centro de Internação Feminina/Centro de Acolhimento Socioeducativo, cuja prática se baseia em oficinas de cerâmica, pintura, fanzines, etc, para estimular produções artísticas em período de recesso escolar das e dos jovens.

4 As autoras destacam que foram observados princípios éticos da prática pedagógica e da pesquisa científica durante a realização das oficinas aqui apresentadas. do Oprimido (1987). Teremos como enfoque na obra de Boal as possibilidades inter-relacionais, disparadoras do campo teatral e necessárias em diálogos sociais. Além dele, a pesquisadora estadunidense Bell Hooks (2013) nos ensina e serve de estímulo a transgredir e a construir regras coletivamente, e isso sem quebrar os acordos ou contratos sociais existentes (mesmo que invisíveis) entre a instituição, as mediadoras artísticas e as internas.

Transitamos entre autoras e autores livremente, sem a pretensão de aprofundamentos teóricos. Esta é uma cartilha que se propõe propositiva ou que nasce com esse objetivo. Pelo reconhecimento das aliadas, pelo estímulo ao olhar, pelo questionamento das regras, pelo desdobrar da vigilância, pelo somar forças e pelo encarar o medo, esta cartilha quer ser um convite à ação. Suas autoras, nós que escrevemos esse texto a seis mãos, somos jovens professoras interessadas na reflexão sobre a ampliação do acesso ao teatro, às artes e à educação. Uma de nós foi facilitadora da oficina teatral, outra participou do projeto de verão e a terceira foi convidada a somar na reflexão sobre as práticas vivenciadas por suas colegas.

As descobertas das jovens em situação de privação de liberdade - que tão cedo já aparentam estarem adormecidas pelo regime de vigilância e pelo contexto de violência em que estão inseridas nos darão pistas sobre as potências da arte. Nosso olhar e os atravessamentos decorrentes das práticas nos conduzem às proposições aqui apresentadas a partir do viés da arte. Arte, a mais forte de nossas aliadas na busca por entusiasmo (HOOKS, 2013) em sala ou cela de aula.

A oficina teatral se deu de agosto de 2019 a fevereiro de 2020 , em uma hora e quinze minutos semanais, e foi conduzida por duas acadêmicas da Universidade do Estado de Santa Catarina (UDESC). Das participantes, quatorze jovens entre quatorze e dezoito anos separadas em duas alas. Segundo a equipe de segurança, a separação se deve a conflitos internos e como estratégia para facilitar a manutenção da ordem - esta mesma que não concordamos.

A separação em duas alas distintas ocorreu também ao longo do projeto de verão, desenvolvido pelo Centro de Educação de Jovens e Adultos (CEJA), durante o recesso escolar. As atividades do projeto foram desenvolvidas por professoras(es) do CEJA (que já estavam lecionando na unidade durante o ano letivo) mas que, no período, atuaram como oficineiras(os). Foram desenvolvidas oficinas de 
cerâmica, fanzine, pintura de tecido, decoupagem, etc. As atividades se deram da segunda quinzena de dezembro até o início de fevereiro, de segunda a sexta-feira, sempre no período da manhã.

\section{Estimule olhares para e no encarceramento -}

As mãos são cruzadas para trás, nas costas, não as vemos; a cabeça fica baixa; o olhar não faz menção de que aparecerá; o corpo é retraído, rígido; a voz é baixa e quase incompreensível, o que dificulta os finais das frases, frases estas que só serão pronunciadas em tom de resposta quando forem questionadas sobre algo. Assim se apresentavam, por entre as grades, os corpos das jovens com quem trabalharíamos, ainda durante pequenas saídas cotidianas: entre uma refeição e outra, entre uma aula e outra, entre uma simples ida ao banheiro... Em nossa primeira semana, ainda em fase de observação, percebemos que a prática pedagógica, de cunho afetuoso como prevíamos efetuar, seria árdua. A dificuldade relatada a partir de olhares das oficineiras de teatro, foi também comum durante 0 Projeto de verão.

Todas as oficinas do Projeto de verão são acompanhadas pelas agentes socioeducativas, 0 que por si só já ocasiona um grande cerceamento da liberdade de ser. Notamos uma dificuldade muito grande em conseguir tornar as oficinas um paralelo de espaço-tempo diferente de tudo aquilo que simboliza aquela instituição. Esse espaço-tempo, afetuoso e acolhedor - no meio de ares que carregam consigo a punição -, foi se concretizando aos poucos, com muita escuta, acolhimento e confiança.

Durante o período em que as atividades artísticas ocuparam a unidade socioeducativa, percebemos a dureza física ser naturalizada e não tão somente perceptível nas e nos jovens, com na equipe de agentes de segurança do local. Rigidez nos parecia ser pressuposto fundamental, um alicerce metodológico do regime socioeducativo. O controle do corpo não diz respeito apenas ao enclausuramento, há o aspecto da perda de potência do corpo, da ausência de expressão. Limitar e enrijecer o corpo revela uma tentativa de apagamento da pessoa. O corpo é signo em sua expressão, comunica não apenas verbalizando. O controle do corpo pela rigidez é, assim, controle de expressão.

Algo necessitava ser feito, era nítido, mas, até que ponto nossa intervenção seria permitida? Nossos passos eram vigiados, e sair da linha colocaria o trabalho em risco. Precisaríamos avançar pelas bordas. Qualquer trabalho que questionasse a lógica punitiva deveria ser feito de modo invisível aos corpos duros e olhares atentos que vigiam e julgam constantemente. Qualquer olhar naquele espaço poderia ser mal interpretado.

O trabalho desenvolvido por Augusto Boal foi companheiro na jornada teatral socioeducativa. Suas obras pareciam ser as aliadas perfeitas às quais poderíamos recorrer na tarefa de sensibilização em espaços como aquele, de restrição de liberdade. Em O Arco-íris do desejo: O método Boal de Teatro e Terapia (1996), o autor apresenta um pensamento sobre a prática que nos conduz a compreender que a escolha por trabalhar ao seu lado é assertiva. Sobre o desenvolvimento de seu Teatro do Oprimido, o autor defende que

\begin{abstract}
O Teatro do Oprimido é um sistema de exercícios físicos, jogos estéticos, técnicas de imagens e improvisações especiais, que tem por objetivo resgatar, desenvolver e redimensionar essa vocação humana, tornando a atividade teatral um instrumento eficaz na compreensão e na busca de soluções para problemas sociais e interpessoais (BOAL, 1996, p. 28-29).
\end{abstract}

Sem evidenciar em princípio questões sociais e interpessoais que nos atravessavam e que, ao mesmo tempo, nos distanciavam da realidade vivenciada por elas, sabíamos que somente o fato de sermos estudantes universitárias a conduzir jogos teatrais naquele espaço causava no grupo certo estranhamento. Abandonar a ingenuidade e o espírito salvacionista que por vezes embaçam o olhar e as práticas em contextos como estes, era além de necessário, urgente, para que a troca se efetivasse genuinamente.

Instauramos gradualmente no espaço de tempo nos destinado (três horas semanais), a sensação de segurança e de confiança, nosso maior desejo enquanto grupo. As jovens nos relatavam, muito através de exercícios e jogos improvisacionais, seus planos para o futuro, assim como as angústias do passado recém vivido, ainda vívido. Conversávamos aos finais das práticas sobre nosso processo artístico, momento em que recebíamos seus retornos quanto aos jogos que gostariam de repetir e os quais, para elas, não haviam funcionado. Era comum ouvir delas, durante o curto espaço de tempo em que o Teatro agia como protagonista, que haviam esquecido de que estavam presas. Segundo elas, percebiam nossa prática quase que como uma agente capaz de abrir fissuras na rotina de vigilância 
constante.

As abordagens corporais, intrínsecas ao fazer teatral, investem na recuperação de uma potência do corpo que não é limitada pelo encarceramento, e aqui parece ser possível reconhecer a importância do teatro nos espaços de restrição de liberdade. $O$ teatro potencializa a conexão entre corpos, mesmo quando não está presente o toque físico e conexão significa ampliação de forças, ampliação da própria potência que é alimentada pelo contato com as demais.

A relevância da ação teatral no espaço se confirmava a cada semana. Estivemos ausentes em uma tarde de chuva intensa na cidade. Impossibilitadas de realizar a prática no dia exato de nosso trabalho, repusemos a aula em outro dia da semana. Ao chegar, fomos surpreendidas mutuamente. Elas ficaram surpresas com nossa ida em dia atípico, e nós mais ainda com a recepção calorosa com que nos presentearam: "A gente achou que vocês haviam desistido da gente. Já estávamos tristes pensando que não teria mais aula de Teatro." Pequenas alegrias que nos fazem acreditar estarmos trilhando o caminho certo, e sem perder de vista o que nos ensinou Augusto Boal: "A profissão teatral, que pertence a poucos, não deve jamais esconder a existência e permanência da vocação teatral, que pertence a todos. O teatro é uma atividade vocacional de todos os seres humanos" (BOAL, 1996, p. 28). Percebíamos que nós, minuciosamente, virávamos nó, e daqueles cegos, que não se desatam fácil.

A cada semana nos aventurávamos mais e testávamos um pouco mais os limites e as restrições impostas pela administração, que até então não demonstrava grande preocupação com nossas ações, mas, até então...

\section{Questione as regras, crie espaços outros}

Não produzir efeitos escolarizantes é abrir espaço para o desconhecido; reduzir o investimento na segurança do mesmo, é querer o outro; não cultivar esperanças que fazem esperar e que consolam (CORRÊA, 2006, p. 28).

A partir das colaborações do professor e pesquisador brasileiro Guilherme Corrêa, que visualiza e trabalha em prol de uma educação não vigilante, por uma desescola (CORRÊA, 2006), encontramos nas oficinas espaços outros de ensino e aprendizagem. Segundo ele,
Uma oficina corresponde sempre a um interesse do oficineiro. Interesse que independe de obrigações que possa ter com o cumprimento de currículos ou por força de sua formação. Não há necessidade de ater-se à sua especialidade ou área de conhecimento. A oficina inicia-se quando se quer conhecer algo (CORRÊA, 2006, p. 27-28).

Nosso intuito era, desde o princípio, ampliar o repertório expressivo das jovens, e nisso incluíamos simples e raras conversas abertas, como nos dias em que optávamos por não jogar teatro, e sim, ouvir as inquietações e reclamações das jovens ação pouco executada naquele espaço. O que propõe a pedagogia das artes, amplamente falando, senão a sensibilização, a expressão e a ampliação da escuta, não é mesmo?

Sim, realizar qualquer atividade em regime socioeducativo cotidianamente é árduo. É um trabalho difícil e cheio de obstáculos. As normas de segurança exigem extremo cuidado com o material que entra e que sai. Contam quantos lápis entram, quantos blocos de papel entram, quantos grampos unem as folhas dos blocos... E, se as contas não batem - se contam números distintos de grampos que entraram e saíram - as agentes de segurança, vigias, instauram um clima de tensão que atrapalha o localizar do bendito grampo. $\mathrm{O}$ ato de encontrar liberdade em espaços de privação de liberdade é como procurar um grampo em um palheiro. A equipe de segurança também avalia nossas roupas, retira nossos acessórios - estes porque poderiam, segundo as normas, tornarem-se uma "arma" nas mãos das jovens que, em sua maioria, nem sequer estão lá por crimes violentos. Pequenos furtos e tráfico fazem parte da realidade da maioria delas. Porém, o sistema se encarrega de retratá-las como jovens criminosas de alto risco.

Contaremos aqui uma de nossas experiências durante o projeto de verão. As agentes socioeducativas disseram que havia uma orientação de que todos os piercings de oficineiras(os) deveriam ser retirados antes da entrada na unidade. Segundo elas, o piercing representava uma ameaça a nossa segurança, porque as jovens poderiam arrancá-lo e usá-lo contra nós. Questionamos tal decisão, pois nunca havíamos retirado nenhum piercing, e, com quatro meses de trabalho na unidade, nada disso havia sido solicitado anteriormente. Novamente reforçaram a ação como medida de segurança, mas também disseram que o fato de usarmos acessórios 
visíveis despertaria a vontade delas de usar piercing também. Estariam então preocupadas com a nossa segurança, ou ocupadas em reprimir os desejos das jovens? Dali em diante, tivemos que tapar nossos piercings com fita toda vez que entrávamos na unidade, o que acabava chamando atenção e despertando curiosidade, exatamente o oposto do que desejava a equipe de segurança.

Dessa vez, o questionamento partiu das próprias jovens: "Porque vocês têm que usar essas fitas aí?". Respondemos com o que as agentes haviam nos informado. Ao ouvirem a resposta, riram com o fato de representarem uma ameaça muito grave e constante. Realmente, as vêem como jovens com alto potencial de violência. Outra coisa que pode ser observada no caso é como o desejo delas (qualquer que seja) deve ser anulado. Segundo essa lógica, não pode existir desejo num sistema punitivista.

A arte, através do conhecimento de si, proporciona, revela e resgata desejos. E o desejo é o que move o humano que existe em nós. Foram muitas as vezes em que elas perceberam como haviam gostado de pintar, de fazer arte com cerâmica e de produzir fanzine a partir de materiais que revelavam aspectos de suas identidades, sendo, assim, significativos para cada jovem. Todos esses produtos da arte, vinham também cheios de afeto e direcionados a pessoas às quais elas gostam muito: como avós, pais e mães. Pintar um pano para poder presentear a avó pode parecer algo simples, mas extremamente afetuoso e grandioso para elas. Um motivo de orgulho no dia da tão aguardada visita. Foram momentos de alegria e de afeto, em que a frieza, ainda que imposta ao nosso cotidiano, foi desvencilhada pelo afeto.

Com a construção de confiança entre oficineiras(os), e através do teatro, as alunas se sentiram mais à vontade para mencionar suas angústias e romper a dureza física e emocional imposta pelo sistema. Jogos, dinâmicas, discussões, estudos, estratégias que permitem com que elas possam ser mais do que jovens atrás das grades. Podem conversar de igual para igual, sem interferência de ordens. Podem olhar no olho. Com o tempo, constroem-se espaços para demonstrações de afeto, cuidado consigo e com a outra.

É extremamente necessário que o olhar seja (re)educado. Através da arte, é possível construir um olhar para o horizonte. Tirar o olhar do chão e alçá-lo à frente, adiante das grades, além dos muros. Mas também para dentro. Dentro de si. Resgatar o desejo e a auto-estima de cada uma delas. E assim, também, estimular a crítica ao mundo que trata de julgá-las e apartá-las do convívio social.

Cientes do potencial que têm, podem optar por trilhar caminhos que as libertem das prisões físicas e simbólicas. Na oficina permanente de Teatro, percebemos que a transformação pode gerar enfrentamentos - pessoais e inter-relacionais. O processo de busca por autonomia e por respeito em ambiente de privação de liberdade pressupõe defrontamentos com hierarquias solidificadas e de difícil penetração. O que não nos impossibilita de efetivar um trabalho sensível e até mesmo afetuoso, só que nos exige paciência. E certo jogo de cintura, como no caso que compartilharemos a seguir.

\section{Desdobre a vigilância: mostre que quem precisa de vigia é o sistema!}

Não é de hoje que as práticas artísticas são diminuídas quando postas em comparação a demais saberes, principalmente os advindos de programas tecnicistas, por exemplo ${ }^{5}$. Em contextos de "ressocialização", essa distinção se potencializa, visto que ali, há o desejo por profissionalização. Tornar nossa oficina "atrativa" para que pudéssemos trabalhar com o mínimo de dignidade possível - isso por parte das agentes de segurança -, exigiu que jogássemos com elas, as mulheres, vigias da prática.

Em determinada aula, em que pretendíamos retomar aspectos que as jovens consideravam cruciais para a atuação, as agentes conversavam e riam alto o suficiente para atrapalharem nossa aula, não conseguíamos nos ouvir por conta do barulho das vigias. Ao solicitar pela terceira vez mais empatia para com o trabalho, e sem obter nenhuma meIhoria, decidimos apelar para o próprio teatro, numa atitude quase rebelde (mesmo que na hora não nos tivesse ocorrido essa palavra) de mostrar que também podemos incomodar - assim como elas. Solicitamos que as jovens pegassem seus blocos de anotação e escrevessem tudo o que viam da grade para fora. As jovens deveriam, então, observar as vigias, anotar seus movimentos, a partir de inspiração em práticas correntes em teatro.

O repertório das oficineiras já informava

5 Soubemos do interesse da instituição socioeducativa em questão pelos cursos técnicos oferecidos por programas como os do Serviço Social da Indústria (SESI), que possuem cursos técnicos direcionados ao mercado de trabalho para jovens e adultos. A parceria entre DEASE e SESI é desejada por parte da primeira instituição, porém, por dificuldades orçamentárias, o projeto é anualmente protelado. 
sobre o desconforto causado pela observação. De modo geral, a postura das pessoas, ao notarem que estão sendo observadas, muda drasticamente em relação a suas ações anteriores. Partindo do pressuposto que a teatralidade é instaurada pelo olhar da(o) observadora (FERAL, 2003), é possível identificar aspectos que apresentam certa teatralidade na esfera cotidiana. Contudo, a percepção do olhar observador, por parte da pessoa observada, opera uma ruptura na sua ação.

De volta ao socioeducativo, ao notar que não conseguiríamos dar continuidade na aula do modo como planejado, e isso pelo barulho das vigias (pois uma coisa é abandonar o plano de aula pelos rumos que a mesma toma, outra completamente diferente é ser impossibilitada de começá-lo), propusemos às jovens a proposta da observação. Elas inicialmente se preocuparam com a possibilidade de serem repreendidas. Assumimos a responsabilidade por eventuais castigos que poderiam lhe ser destinados, e as sete jovens pararam na grade. No início, as vigias acharam graça, fizeram poses pensando estarem sendo desenhadas, mas, com o silêncio das jovens, perceberam o quanto a vigilância perturba. Em menos de três minutos as vigias arrumaram o que fazer e os corredores voltaram a ser silenciosos. Seguimos então o rumo da aula, agora a partir do que as jovens haviam anotado. Por fim, as vigias contribuíram com a nossa oficina, mesmo sem saber.

Talvez a prática de oficinas em espaços de privação de liberdade exija que as oficineiras desenvolvam certa habilidade para percorrerem suas próprias trajetórias, como estratégias para mostrar ao sistema o quão falhas e unilaterais são suas regras. $\mathrm{Na}$ semana seguinte à essa aula específica (de observação ao contrário), recebemos pedidos comovidos de desculpas de todas as vigias pelos ruídos na aula anterior. $\mathrm{O}$ fato de terem se responsabilizado por prejudicar a aula comprovou, ao nosso ver, que a oficina de teatro pode intervir, mesmo que minimamente, na ordem dada:

Como processo criativo, a disciplina do teatro pode ser uma experiência de liberdade que se opõe àquela da vida na prisão, que é de constrangimento e anulação do próprio preso. A experiência criativa pode ser libertária para a constituição do sujeito, pela inclusão e afirmação da identidade; ao contrário da experiência da carceragem, que é de abjeção completa do homem. A disciplina do teatro constrói sujeitos de decisão, ao contrário da prisão, que torna o homem um objeto de submissão (ROCHA, 2009, s/p.).

\section{Some forças para ampliar o acesso}

A estrutura social em que vivemos insiste no aspecto individual e pouco a pouco nos distanciamos do sentido do coletivo e da perspectiva de comunidade. Mas não só vivemos comunitariamente - em uma trama de inter-relações culturalmente sustentadas e estruturadas - como criamos comunitariamente, inclusive na invenção de modos de viver e conviver. Como seres culturais, somos seres sociais.

Ao se tornar consciente de sua existência individual, o homem não deixa de conscientizar-se também de sua existência social, ainda que esse processo não seja vivido de forma intelectual. O modo de sentir e de pensar os fenômenos, o próprio modo de sentir-se e pensar-se, de vivenciar as aspirações, os possíveis êxitos e eventuais insucessos, tudo se molda segundo idéias e hábitos particulares ao contexto social em que se desenvolve o indivíduo (OSTROWER, 1977, p. 16-17).

Relembrar a ideia de comunidade pode nos fornecer um importante sustento no sentido de encontrarmos, criarmos e alimentarmos parcerias em prol de nossos objetivos. Para isso é importante aguçar a sensibilidade para perceber as pessoas que estão por perto e às quais podemos nos unir, sejam em parcerias duradouras, sejam em parcerias momentâneas. Trata-se de observar com atenção quem busca a ampliação dos acessos àquilo que é básico e direito de cada pessoa: a educação, a cultura, a arte (para nos restringirmos aos temas mais tocados neste escrito). Mesmo uma parceria momentânea e efêmera tem potência de transformação, uma vez que cada pequena ação traz em si a semente que pode germinar em outras terras.

Muitas vezes podemos nos desmotivar com a efemeridade dos encontros, diminuindo previamente seu valor por entendê-los como breves e sem possibilidade de continuidade. Nos contextos que aqui tocamos, de espaços de privação de liberdade, é comum que os grupos sejam inconstantes, com trocas e alta rotatividade de pessoas que deixam a presença da ausência como uma marca nas oficinas e nos encontros. Há sempre a lembrança da provisoriedade, a insegurança quanto ao futuro, o desalento dos laços que não chegam a se fortalecer pois logo são cortados bruscamente. Aqui propomos a 
necessidade do contínuo exercício de reconhecer a potência de cada dia e de cada encontro, assumindo uma efemeridade tão próxima aos artistas e pessoas do teatro: acaba a apresentação e o acontecimento cênico já não existe mais. No dia seguinte, poderá haver nova apresentação, mas será um novo acontecimento, único e singular. No intervalo de uma hora algo nasceu e morreu.

Defendemos a ideia de que pessoas que partilham momentaneamente um mesmo território podem e devem acreditar na construção de algo coletivo. É preciso criar comunidades com o foco no tempo presente, projetando o futuro como a possibilidade de que essa comunidade se espalhe e se multiplique (BEY, 2018), mas sem abrir mão de sua concretização no aqui e agora do território que se ocupa junto com outras pessoas. Trata-se de assumir a fluidez do espaço, assumir seus trânsitos e atravessamentos. Não só as pessoas que ali estão em situação de detenção podem não mais ali estar na próxima semana, mas quem passa por esse espaço semanalmente como facilitadora de alguma proposta pode ter seu acesso negado. Que isso não nos impeça de artesanalmente construir comunidades.

Petra Kuppers, artista, professora e ativista da deficiência, que não por acaso tem em suas referências os brasileiros Paulo Freire e Augusto Boal, destaca a perspectiva das comunidades de criação cênica, em que o coletivo, a diversidade, a auto expressão e a mudança política caminham lado a lado.

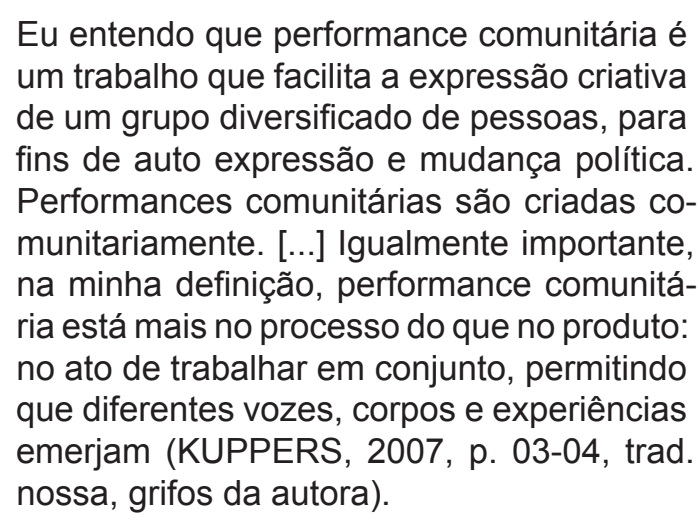

Compreendemos que criar comunitariamente parte da ideia de estabelecer comunidades, que, por sua vez, significa estabelecer algo com outras pessoas, horizontalmente, partilhando saberes e repertórios diversos mas igualmente importantes. Trata-se de aprender com o encontro, aprender na relação e nessa relação fortificar a ideia de que é coletivamente, comunitariamente, que se ampliam os acessos e se mobilizam estruturas de poder. Trata-se de reconhecer que comunidade é sinônimo de alteridade: a sintonia que nos aproxima sem apagar as nossas diferenças, sem qualificá-las, sem hierarquizá-las, sem dominá-las.

A proposta de construir comunidades em espaços que inicialmente poderiam ser áridos ao contato e às parcerias nos parece uma chave para a ampliação do acesso às artes, à educação e à cultura, uma vez que, tendo uma pessoa acesso a esses recursos, abre-se o convite às demais. Não estamos indicando aqui a dependência hierárquica, autoritária e colonizadora, mas uma inter-relação, um convite a acessar juntas um espaço talvez antes negado ou desconhecido.

Através das práticas artísticas, observamos que o processo artístico-pedagógico é atravessado pelas pessoas que se propõem aos atos formativos, mas também que os questionam em seus formatos rígidos e tradicionais. Nesse questionamento talvez seja possível fazer reviver outros modos de circulação de saberes, forjando práticas pedagógicas que são um convite à ampliação do acesso pelo fazer de cada uma a partir do território que cada uma ocupa naquele momento, um território que é geográfico mas também é território de pertencimento - fluído e sustentado pelas redes comunitárias. Perceber esse território implica olhar de outro modo para o local que se habita.

O teatro, por seu caráter de jogo que coloca em suspensão o tempo e espaço - suspendendo o espaço real em prol de um espaço ficcional quando no jogo o local deixa de ser aquilo para ser outra coisa - pode nos auxiliar a desvelar os conteúdos dos territórios, suas raízes, suas marcas e seus propósitos. Por meio do jogo, mobilizam-se territórios coletivos e individuais - o próprio corpo é território. Finda-se o jogo, o espaço real retorna em toda sua concretude (do concreto da realidade e do concreto da parede do cárcere), no entanto, nos questionamos se nesse retorno o espaço segue o mesmo ou foi modificado. O jogo causa uma certa desorientação, uma perda de território momentânea, uma suspensão de identidades (elas também, vinculadas a territórios: quem está na prisão é prisioneira, criminosa; quem está na universidade é universitária, estudante). Nos perguntamos: para onde pode nos levar essa desorientação?

\section{Encare o medo, forneça seus olhos ao olhar das outras}

Para Augusto Boal, o centro de gravidade do 
teatro é a inter-relação: a conexão específica entre pessoas. Essa inter-relação se traduzia, para o teatrólogo brasileiro, pelo olho no olho.

Para mim, sempre foi esse o alicerce de todo espetáculo: dois atores se olhando. $\mathrm{O}$ olho é a parte mais vulnerável do corpo-humano! Por isso procuramos, recatados, esconder nossos olhos em momentos de emoção. Ou oferece-los, em momentos de amor. Os atores devem-se oferecer seus olhares (BOAL, 2000, p. 142).

No entanto, como destaca Boal, abrir o olhar à outra significa colocar-se em estado de vulnerabilidade. Assim, da importância de abrir-se ao olhar da outra na aula de teatro se soma a urgência da proteção no espaço de privação de liberdade. No cárcere a vulnerabilidade não é bem vista. Aqui, primeiro exercício da facilitadora: ser aquela que inicialmente age oferecendo seu olhar. Oferecendo seu olhar como quem faz um convite ao desconhecido. Essa ação que propomos não é fácil e nem automática. É preciso esforço para encarar nosso próprio medo, medo do desconhecido e medo de nos colocarmos vulneráveis em um espaço no qual também estamos sob vigilância. A facilitadora, ao adentrar o espaço de privação de liberdade, fica sob observação dupla: é observada pelas vigias e é observada pelas jovens. Nesse momento, quando o olho no olho estimula que nos fechemos, que busquemos uma pretensa proteção na máscara fria que nos foi indicado usar nesse local, as práticas cênicas podem nos auxiliar a encontrar a abertura para partilhar nosso medo.

Ann Cooper Albright, performer, professora e pesquisadora, apresenta uma prática proposta em suas oficinas de Contato Improvisação: basicamente, a indicação sugere deixar a imagem do mundo invadir os olhos ao invés de buscar captar as imagens. Para Albright (2013), essa simples mudança de intenção e imaginação do olhar muda a percepção para "se ver no mundo" e não apenas "ver o mundo de seu ponto de vista". Ao abrir o olhar para a parceira de jogo, parceira de aula, parceira de cela, temos a possibilidade de nos vermos na relação ali estabelecida, reconhecendo nossos medos revisitados nos olhos das demais. Nesse entre que se estabelece na troca, nossos olhos se cruzando e reconhecendo um espaço em comum, o medo pode ser ressignificado e questionado, assim como nossas noções estáticas de eu/outra.
Ao mudarmos nossa imaginação somática, podemos reordenar nossas noções culturais de individualidade. Ao contrário do paradigma colonialista do indivíduo, impulsionado por sua vontade e determinação de sair para o mundo e reivindicar (estar em seus próprios pés, deixar uma marca etc), o self torna-se uma parte interdependente que flui pelo e com o mundo (ALBRIGHT, 2013, p. 58-59).

A perspectiva do entre, da interação, vislumbrada em Boal e Albright a partir de práticas cênicas, de teatro e de dança, respectivamente, nos possibilita pensar sobre a interação forjando as individualidades e mesmo as categorias nas quais localizamos e - por que não - aprisionamos as pessoas.

Para o sociólogo canadense Howard Becker os comportamentos sociais operam pela interação entre as pessoas, assim se dando a categorização entre desviante (para quem está fora das normas) ou não. É da interação que nascem as regras e delas a exigência por seu cumprimento. "Desvio não é uma qualidade que reside no próprio comportamento, mas na interação entre a pessoa que comete um ato e aquelas que reagem a ele" (BECKER, 2008 , p. 27). As práticas cênicas, assim, podem se revelar como um espaço seguro de ensaiar outros modos de relação, ou, outros modos de percepção dessas relações, compreendendo as interações e consequentes categorizações como fluidas, móveis, momentâneas.

Reconhecer o entre, a conexão que sempre se estabelece entre eu/mundo e eu/outra, e que pode iniciar com o encontro de olhos receosos, pode nos auxiliar a uma reorganização de nossas percepções frente ao desconhecido e ao receio de experimentar a vulnerabilidade. O exercício de abrir-se ao olhar da outra, no entanto, não se dá como um convite perigoso. Ocorrendo por meio da prática cênica, esse convite conta com a segurança do jogo e com o investimento das demais pessoas que partilham $o$ ato de jogar. Assim, trama-se uma complexa rede em que o desconhecido e a segurança coexistem, e em que pode-se deslocar o foco da observação pela vigilância para a observação pelo prazer. Prazer de jogar, de forjar um espaço que, ainda que efêmero, convida a se revelar à outra descobrindo-se parte de algo, revelando-se aos olhos das demais para encontrar ali uma parte de si.

Fornecer os nossos olhos como espelhos para as pessoas que conosco partilham espaços pode nos fortalecer como coletivo, nos informando 
que encarar o medo coletivamente pode ser um convite à sua ressignificação e, também, um convite para nos vermos para além do medo. Somos potência e o encontro de nossos olhares pode auxiliar a que nos lembremos disso.

Essa cartilha é nossa tentativa de traduzir em palavras as ações a que nos propomos. Cada uma das ações apresentadas tem como objetivo forjar uma pedagogia que atravesse as grades. São as práticas criativo-pedagógicas o nosso meio para a ação. Porém, pretendemos que pessoas de outras áreas, que desenvolvem práticas e processos em ambientes de privação de liberdade, possam encontrar aqui um convite à contaminação, ou seja, de que as ações que destacamos pelo viés artístico possam ser articuladas de acordo com diversos objetivos. Ressaltamos serem incontáveis as ações (como as que propomos) para que talvez cheguemos a uma sociedade sem ambientes punitivistas, sem vigilâncias, sem opressões. Entretanto, nossa vontade de mudança radical não termina aqui, e nos propomos a seguir buscando estratégias que revelem as construções sociais que levam ao aprisionamento de corpos e à própria existência da instituição prisão. Se você que nos lê agora se insere em ambientes de privação de liberdade, há uma chance de que sejamos parceiras insurgentes, e desejamos que nossas palavras ecoem como um convite à ação.

\section{Referências}

ALBRIGHT, Ann Cooper. Caindo na memória. In: ISAACSSON, Marta (Org.); MASSA, Clóvis Dias; SPRITZER, Mirna; SILVA, Suzane Weber da. Tempos de memória: vestígios, ressonâncias e mutações. Porto Alegre: AGE, p. 49-67, 2013.

BECKER, Howard S. Outsiders. Estudos de sociologia do desvio. Rio de Janeiro: Zahar, 2008.

BEY, Hakim. TAZ - Zona Autônoma Temporária. São Paulo: Veneta, 2018.

BOAL, Augusto. Hamlet e o filho do padeiro: memórias imaginadas. Rio de Janeiro: Record, 2000.

BOAL, Augusto. O arco-íris do desejo: método Boal de Teatro e Terapia. Rio de Janeiro: Civilização Brasileira, 1996.

CORRÊA, Guilherme Carlos. Educação comunica- ção anarquia: procedências da sociedade de controle no Brasil. São Paulo: Editora Cortez, 2006.

FÉRAL, Josette. Acerca de la teatralidad. Buenos Aires: Nueva Generación, 2003.

HOOKS, Bell. Ensinando a transgredir: a educação como prática da liberdade. São Paulo: Editora WMF Martins Fontes, 2013.

KUPPERS, Petra. Community Performance: an introduction. New York: Routledge, 2007.

OSTROWER, Fayga. Criatividade e processos de criação. Rio de Janeiro: Imago Editora Ltda, 1977.

ROCHA, Maria de Lourdes Naylor. Teatro na prisão: uma experiência pedagógica. O Percevejo Online, v. 1, n. 2, 2009. Disponível em: http://www.seer.unirio. br/index.php/opercevejoonline/article/view/601/596. Acessado em: 20 nov. 2020.

Recebido: 23/03/2021

Aceito: 18/10/2021

Aprovado para publicação: 08/11/2021

Este é um artigo de acesso aberto distribuído sob os termos de uma Licença Creative Commons Atribuição 4.0 Internacional. Disponível em: http://creativecommons.org/licenses/by/4.0.

This is an open-access article distributed under the terms of the Creative Commons Attribution License 4.0 International. Available at: http://creativecommons.org/licenses/by/4.0.

Ce texte en libre accès est placé sous licence Creative Commons Attribution 4.0 International. Disponible sur: http://creativecommons.org/licenses/by/4.0. 